\title{
Editorial
}

\section{Management of incidental cerebral AVMs in the post-ARUBA era}

Mohamed Samy Elhammady, M.D., and Roberto C. Heros, M.D.

\section{University of Miami, Department of Neurosurgery, Miami,} Florida

In this issue of the Journal of Neurosurgery, Yen and colleagues present a series of 31 patients with incidentally discovered arteriovenous malformations (AVMs) that were treated with Gamma Knife surgery (GKS) at the University of Virginia over a 20 -year period. ${ }^{22}$ This article is important given the ongoing controversy regarding the management of unruptured AVMs, particularly in light of the recent results of the interim analysis of the ARUBA study (A Randomized Trial of Unruptured Brain Arteriovenous Malformations). ${ }^{14}$ In this series of 31 patients, the Spetzler-Martin grading at the time of initial GKS was Grade I in 4 patients, Grade II in 13 patients, Grade III in 12 patients, and Grade IV in 2 patients. Preradiosurgical embolization was performed in 5 patients. The overall mean nidus volume was $3.6 \mathrm{~cm}^{3}$ and the median marginal dose was $20 \mathrm{~Gy}$. The mean clinical, MRI, and angiographic follow-up was 78, 54, and 57.5 months, respectively. Four patients underwent repeat GKS at a mean of 6.8 years after the initial procedure.

The authors reported an overall AVM obliteration rate of $84 \%(\mathrm{n}=26$ patients) based on angiography $(\mathrm{n}=$ $19)$ or MRI $(n=7)$. The actuarial obliteration rate was $55 \%$ and $78 \%$ at 3 and 5 years, respectively. The only factor to independently predict AVM obliteration in multivariate analysis was small nidus volume. Although radiation-induced imaging changes were observed in $42 \%$ (n $=13$ ) of the patients at a mean of 13.7 months from treatment, only 2 patients developed symptoms that completely resolved after a short course of steroids. Hemorrhage occurred in 2 patients during the latency period following GKS and resulted in permanent hemiparesis in 1 . The authors reported an annual postradiosurgical hemorrhage rate of $1.7 \%$. There were no deaths reported in this series.

The article has some limitations such as the small patient population, the retrospective nature of the review, and the possible selection and referral biases that may limit the general applicability of the results. Furthermore, in $27 \%$ of the patients, AVM obliteration was determined by MRI criteria alone, which may have overestimated the overall reported obliteration rates. Finally, as the authors acknowledge, radiosurgical techniques have evolved over the study period. However, this final point should, if anything, improve the already excellent results and safety profile of radiosurgery reported by the authors. Despite these limitations, the authors should be commended on an excellent and carefully performed study.

In general, the management of cerebral AVMs is based on a thorough understanding of the natural history as well as the risks of intervention. A number of studies have evaluated the natural history of cerebral AVMs with regards to risk of hemorrhage (Table 1). Based on data from early natural history series, neurosurgeons for many years believed that the annual rupture rate for cerebral AVMs was approximately $2 \%-4 \%$. The rebleeding rate was presumed to increase slightly to approximately $6 \%$ during the first year following hemorrhage, after which the annual hemorrhage rate became similar to an AVM that had not bled. More recent data, particularly from 2 large databases at the University of Helsinki and Columbia University, have challenged the notion that the annual hemorrhage rate was similar for ruptured and unruptured AVMs. ${ }^{8,21}$ Such data, in fact, provided the impetus for conducting the ARUBA trial. The authors discuss well the limitations of the recent results of the ARUBA trial and their comments coincide well with those expressed by us in a recent editorial. ${ }^{4}$

Despite the substantial limitations of the ARUBA trial, most likely the majority of the non-neurosurgical community will not look beyond the conclusion of the study, which was that intervention for unruptured cerebral AVMs carries significantly greater morbidity than observation. This can potentially make it extremely difficult for neurosurgeons to convince community physicians and patients harboring unruptured AVMs of the need for intervention. We would like to comment on our current management of unruptured cerebral AVMs in the postARUBA era and in the context of the results of the current study. In our opinion, patients with Spetzler-Martin Grade I and II AVMs should still be offered surgical excision provided that they are relatively young and healthy. Given the more benign natural history of unruptured AVMs, the threshold for age and general health are higher than that for ruptured lesions. Surgery in low-grade AVMs is very safe and offers the patient an immediate cure. ${ }^{9,15,19,20}$ However, as demonstrated by the results of the current study, radiosurgery for unruptured AVMs can provide a relatively high chance of nidal obliteration with an acceptably low risk of symptomatic radiation adverse effects or 
TABLE 1: Natural history studies of AVMs

\begin{tabular}{|c|c|c|c|c|}
\hline Authors \& Year & Type of Study & $\begin{array}{l}\text { No. of } \\
\text { Patients }\end{array}$ & $\begin{array}{l}\text { Average } \\
\text { Follow-Up }\end{array}$ & Annual Hemorrhage Rate \\
\hline Graf et al., 1983 & retrospective & 191 & $4.8 \mathrm{yrs}$ & $\begin{array}{l}2-3 \% \text { in patients w/o hemorrhage; } 6 \% \text { at } 1 \text { st yr after hemorrhage, then } \\
2 \% \text { in patients } w / \text { hemorrhage }\end{array}$ \\
\hline Crawford et al., 1986 & retrospective & 217 & $10.4 \mathrm{yrs}$ & $2 \%$ \\
\hline Brown et al., 1988 & retrospective & $\begin{array}{l}168 \text { (all un- } \\
\text { ruptured) }\end{array}$ & $8.2 \mathrm{yrs}$ & $2.2 \%$ \\
\hline Mast et al., 1997 & prospective & 281 & $1.0 \mathrm{yrs}$ & $2.2 \%$ in patients w/o hemorrhage, $17.8 \%$ in patients w/ hemorrhage \\
\hline Halim et al., 2004 & retrospective & 790 & $4.0 \mathrm{yrs}$ & $7 \%$ for 1 st yr, then $3 \%$ \\
\hline Stapf et al., 2006 & prospective database & 622 & 102 days & $1.3 \%$ for unruptured AVMs, $5.9 \%$ for AVMs presenting w/ hemorrhage \\
\hline Hernesniemi et al., 2008 & retrospective & 238 & $13.5 \mathrm{yrs}$ & $\begin{array}{l}2.4 \% \text { overall; } 1 \text { st } 5 \text { yrs, } 4.6 \% \text { (risk factors previous hemorrhage \& } \\
\text { deep location); subsequent yrs, } 1.6 \% \text { (risk factors previous hem- } \\
\text { orrhage, deep or infratentorial location, \& large size) }\end{array}$ \\
\hline
\end{tabular}

postradiosurgical hemorrhage and may be a reasonable alternative, particularly in older patients or in patients with significant surgical comorbidities. Although a high rate of curative embolization with acceptable morbidity for Grade I and II has been reported, ${ }^{18}$ in our opinion, embolization with an intention to cure should be reserved for select cases and performed only at institutions with significant experience in the technique. Treatment decisions regarding Grade III AVMs are not straightforward because they not only represent a transition between lowgrade (I and II) and high-grade (IV and V) AVMs but also have long been recognized as a heterogeneous group of lesions with varying treatment morbidity rates. ${ }^{3,11,17} \mathrm{We}$ have discussed the management of Grade III AVMs in a previous editorial. ${ }^{4}$ Suffice it to say here that with unruptured Grade III AVMs the predicted safety of invasive treatments such as resection, frequently preceded by embolization, should be very high for such treatments to be recommended. This article offers good evidence that the less invasive radiosurgical treatment may be an alternative option, particularly for the smaller Grade III lesions. The vast majority of unruptured Grade IV and V lesions should be treated conservatively as resection is associated with serious morbidity and the chance of complete obliteration with multimodal therapy is low. ${ }^{7}$ Furthermore, most evidence suggests that partial AVM obliteration does not improve the natural history of these lesions and may actually make it worse, and therefore we do not recommend it as a sole treatment. ${ }^{7,10,13}$ Palliative embolization may be considered in select cases to target high-risk angiographic features or reduce AVM flow in patients with intractable headaches or progressive neurological deficits related to arterial steal or venous hypertension.

Finally, we would like to emphasize the fact that this excellent and busy radiosurgical center has treated only 31 patients with unruptured AVMs during a period of time when a total of 1400 AVM patients were treated. To us this implies not only that they have been very conservative in using radiosurgery for unruptured AVMs, but also that they have used excellent judgment in selection and have probably recommended either no treatment for very large complex AVMs (Grade IV and V) or surgical excision for Grade I and II AVMs in noneloquent locations. In fact, the senior author of this editorial has treated several patients with AVMs from this area that had been initially referred for radiosurgery to the late Professor Steiner, the founder of the Gamma Knife unit at the University of Virginia. With his impeccable judgment and ethical standards, Dr. Steiner kindly referred these patients to us after telling them that in their cases radiosurgery was not indicated and surgical excision was the treatment of choice. We know that he would have been very, very proud of this excellent article by his successors at this prestigious institute. We heartily congratulate them.

(http://thejns.org/doi/abs/10.3171/2014.3.JNS14135)

\section{Disclosure}

The authors report no conflict of interest.

\section{References}

1. Brown RD Jr, Weiber DO, Forbes G, O'Fallon WM, Piepgras DG, Marsh WR, et al: The natural history of unruptured intracranial arteriovenous malformations. J Neurosurg 68:352357, 1988

2. Crawford PM, West CR, Chadwick DW, Shaw MD: Arteriovenous malformations of the brain: natural history in unoperated patients. J Neurol Neurosurg Psychiatry 49:1-10, 1986

3. de Oliveira E, Tedeschi H, Raso J: Multidisciplinary approach to arteriovenous malformations. Neurol Med Chir 38 Suppl: 177-185, 1988

4. Elhammady MS, Heros RC: Editorial. Stereotactic radiosurgery for Spetzler-Martin Grade III arteriovenous malformations. J Neurosurg 120:970-972, 2014

5. Graf CJ, Perret GE, Torner JC: Bleeding from cerebral arteriovenous malformations as part of their natural history. J Neurosurg 58:331-337, 1983

6. Halim AX, Johnston SC, Singh V, McCulloch CE, Bennett JP, Achrol AS, et al: Longitudinal risk of intracranial hemorrhage in patients with arteriovenous malformation of the brain within a defined population. Stroke 7:1697-1702, 2004

7. Han PP, Ponce FA, Spetzler RF: Intention-to-treat analysis of Spetzler-Martin Grades IV and V arteriovenous malformations: natural history and treatment paradigm. J Neurosurg 98:3-7, 2003 


\section{Editorial}

8. Hernesniemi JA, Dashti R, Juvela S, Väärt K, Niemela $M$, Laakso A: Natural history of brain arteriovenous malformations: a long-term follow-up study of risk of hemorrhage in 238 patients. Neurosurgery 63:823-829, 2008

9. Heros RC, Korosue K, Diebold PM: Surgical excision of cerebral arteriovenous malformations: late results. Neurosurgery 26:570-578, 1990

10. Kwon O, Han DH, Han MH, Chung YS: Palliatively treated cerebral arteriovenous malformations: follow-up results. J Clin Neurosci 7 Suppl 1:69-72, 2000

11. Lawton MT: Spetzler-Martin Grade III arteriovenous malformations: surgical results and a modification of the grading scale. Neurosurgery 52:740-749, 2003

12. Mast H, Young WL, Koennecke HC, Sciacca RR, Osipov A, Pile-Spellman J, et al: Risk of spontaneous haemorrhage after diagnosis of cerebral arteriovenous malformation. Lancet 350:1065-1068, 1997

13. Miyamoto S, Hashimoto N, Nagata I, Nozaki K, Morimoto M, Taki W, et al: Posttreatment sequelae of palliatively treated cerebral arteriovenous malformations. Neurosurgery 46:589 595,2000

14. Mohr JP, Parides MK, Stapf C, Moquete E, Moy CS, Overbey JR, et al: Medical management with or without interventional therapy for unruptured brain arteriovenous malformations (ARUBA): a multicentre, non-blinded, randomised trial. Lancet 383:614-621, 2014

15. Morgan MK, Rochford AM, Tsahtsarlis A, Little N, Faulder KC: Surgical risks associated with the management of Grade I and II brain arteriovenous malformations. Neurosurgery 54: 832-837, 2004

16. Ondra SL, Troupp H, George ED, Schwab K: The natural history of symptomatic arteriovenous malformations of the brain: a 24-year follow-up assessment. J Neurosurg 73:387391, 1990

17. Pandey P, Marks MP, Harraher CD, Westbroek EM, Chang SD, Do HM, et al: Multimodality management of SpetzlerMartin Grade III arteriovenous malformations. Clinical article. J Neurosurg 116:1279-1288, 2012

18. Saatci I, Geyik S, Yavuz K, Cekirge HS: Endovascular treatment of brain arteriovenous malformations with prolonged intranidal Onyx injection technique: long-term results in 350 consecutive patients with completed endovascular treatment course. Clinical article. J Neurosurg 115:78-88, 2011

19. Sisti MB, Koder A, Stein BM: Microsurgery for 67 intracranial arteriovenous malformations less than $3 \mathrm{~cm}$ in diameter. J Neurosurg 79:653-660, 1993

20. Spetzler RF, Martin NA: Proposed grading system for arteriovenous malformations. J Neurosurg 65:476-483, 1986

21. Stapf C, Mast H, Sciacca RR, Choi JH, Khaw AV, Connolly ES, et al: Predictors of hemorrhage in patients with untreated brain arteriovenous malformation. Neurology 66:1350-1355, 2006

22. Yen CP, Ding D, Cheng CH, Starke RM, Shaffrey M, Sheehan J: Gamma Knife surgery for incidental cerebral arteriovenous malformations. Clinical article. J Neurosurg [epub ahead of print August 22, 2014. DOI: 10.3171/2014.7.JNS131397]

\section{Response}

Robert M. Starke, M.D., M.Sc., ${ }^{1}$ Dale Ding, M.D., ${ }^{1}$ Chun-Po Yen, M.D., ${ }^{1}$ And Jason P. Sheehan, M.D., Ph.D. ${ }^{1,2}$

${ }^{1}$ Department of Neurological Surgery, and ${ }^{2}$ Department of Radiation Oncology, University of Virginia, Charlottesville, Virginia

We appreciate the authors' interest in our recent study. In their editorial, the authors shed additional light on the natural history studies for AVMs. It should be noted that truly incidental vascular lesions are likely on the rise as MRI access increases and MRI technology improves. $^{2}$ In a recent meta-analysis, the mean prevalence of non-neoplastic incidental findings including AVMs on brain MRI was $2.0 \%$ (range $1.1 \%-3.1 \%$ ). ${ }^{5}$ Many of the natural history studies cited by the authors and detailed in Table 1 in their editorial were not comprised of truly incidental AVMs. As such, the conventional wisdom that the annual rupture rate for cerebral AVMs is $2 \%-4 \%$ may not hold true for incidentally found AVMs. It is quite likely that the hemorrhage rate is higher for previously ruptured AVMs than unruptured but symptomatic ones. Furthermore, the hemorrhage rate for unruptured but symptomatic AVMs is likely higher than for unruptured and asymptomatic (i.e., incidental) AVMs. Although it is easier to homogenize AVMs to assess overall hemorrhage rates, each lesion must be assessed individually as hemorrhage rates may vary from less than $1 \%$ to $35 \%$ per year depending on associated high-risk angioarchitectural features. ${ }^{6,7}$ Regardless, any intervention for incidental AVMs truly must surpass a high bar.

As the authors note, many clinicians, health care policy makers, and private payers will likely view the current findings of ARUBA as evidence that intervention for unruptured cerebral AVMs carries far greater morbidity than conservative management. ${ }^{4}$ In this study, the primary outcomes in those receiving treatment for SpetzlerMartin Grade I (14.3\%), Grade II (43.3\%), and Grade III $(57.1 \%)$ lesions were unacceptably high. ${ }^{8,9}$ Of the AVMs receiving a single treatment, $30(46 \%)$ of 66 underwent embolization despite the relatively higher risks of embolization with a low potential for curative occlusion. The majority of hemorrhages occurred in patients who were initially treated with embolization and had incompletely obliterated AVMs. The number of patients treated only with microsurgery or radiosurgery comprised a minor proportion of the interventional cohort (31\%). The $31 \mathrm{pa}-$ tients with incidental AVMs reported in our study represent a small fraction of the now greater than 1500 treated at our institution with radiosurgery, and significantly larger overall cohort of AVMs treated using any modality. Unfortunately, the limited number of patients in ARUBA does not allow stratification of outcomes based on treatment received.

Neurosurgeons have, at times, exhibited a cavalier attitude toward those questioning the value of the interventions that we perform. Given the well-described natural history of AVMs, the very notion that we must demonstrate the merits of intervention for an AVM may appear counterintuitive to neurosurgeons. Fortunately, the National Neurosurgery Quality and Outcomes Database $\left(\mathrm{N}^{2} \mathrm{QOD}\right)$ was developed to generate data that would shed light on the quality and effectiveness of neurosurgical procedures. ${ }^{3}$ Multicenter, prospective data through such a registry effort can demonstrate the effectiveness of our approaches when they prove successful. Moreover, the registry may also reveal the indications, approaches, patient characteristics, or disease-specific attributes for which our skills fall short of providing an acceptable outcome. A fairly substantial effort is underway to em- 
bark upon a national quality and outcomes registry for stereotactic radiosurgery, and AVMs would be the focus of this registry. Similarly, efforts are being developed for evaluating the outcomes associated with AVM microsurgical and endovascular approaches. ${ }^{1}$ Our future role in the management of patients with AVMs will likely be determined based upon a thorough understanding of the natural history of various types of AVMs (e.g., ruptured vs unruptured, symptomatic vs asymptomatic) and the objective value that we can demonstrate for our interventions in specific AVM patient cohorts.

\section{References}

1. Asher AL, McCormick PC, Selden NR, Ghogawala Z, McGirt MJ: The National Neurosurgery Quality and Outcomes Database and NeuroPoint Alliance: rationale, development, and implementation. Neurosurg Focus 34(1):E2, 2013

2. Komotar RJ, Starke RM, Connolly ES: Brain magnetic resonance imaging scans for asymptomatic patients: role in medical screening. Mayo Clin Proc 83:563-565, 2008

3. McGirt MJ, Speroff T, Dittus RS, Harrell FE Jr, Asher AL: The National Neurosurgery Quality and Outcomes Database $\left(\mathrm{N}^{2} \mathrm{QOD}\right)$ : general overview and pilot-year project description. Neurosurg Focus 34(1):E6, 2013

4. Mohr JP, Parides MK, Stapf C, Moquete E, Moy CS, Overbey JR, et al: Medical management with or without interventional therapy for unruptured brain arteriovenous malformations
(ARUBA): a multicentre, non-blinded, randomised trial. Lancet 383:614-621, 2013

5. Morris Z, Whiteley WN, Longstreth WT Jr, Weber F, Lee YC, Tsushima Y, et al: Incidental findings on brain magnetic resonance imaging: systematic review and meta-analysis. BMJ 339:b3016, 2009

6. Ogilvy CS, Stieg PE, Awad I, Brown RD Jr, Kondziolka D, Rosenwasser R, et al: AHA Scientific Statement: Recommendations for the management of intracranial arteriovenous malformations: a statement for healthcare professionals from a special writing group of the Stroke Council, American Stroke Association. Stroke 32:1458-1471, 2001

7. Stapf C, Mast H, Sciacca RR, Choi JH, Khaw AV, Connolly ES, et al: Predictors of hemorrhage in patients with untreated brain arteriovenous malformation. Neurology 66:1350-1355, 2006

8. Starke RM, Komotar RJ, Hwang BY, Fischer LE, Garrett MC, Otten ML, et al: Treatment guidelines for cerebral arteriovenous malformation microsurgery. Br J Neurosurg 23:376386, 2009

9. Starke RM, Komotar RJ, Hwang BY, Fischer LE, Otten ML, Merkow MB, et al: A comprehensive review of radiosurgery for cerebral arteriovenous malformations: outcomes, predictive factors, and grading scales. Stereotact Funct Neurosurg 86:191-199, 2008

Please include this information when citing this paper: published online August 22, 2014; DOI: 10.3171/2014.3.JNS14135. 